\title{
Fatal case of cerebral aspergilloma complicated by ventriculitis and bacteremia due to Salmonella species in a sickle cell disease patient
}

Fawzia E. Alotaibi, MD, MBBS.

\begin{abstract}
يصف هذا التقرير حالة ميتة من التهاب الجيوب الأنفية الفطري Aspergillus flavus

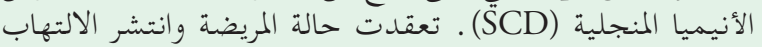

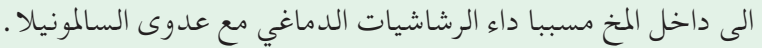

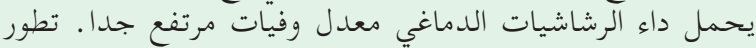

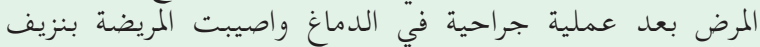

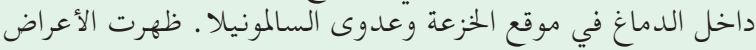

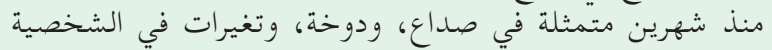

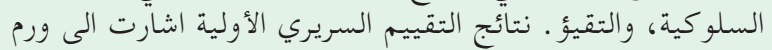

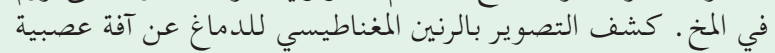

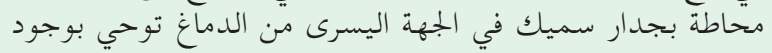

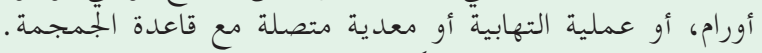

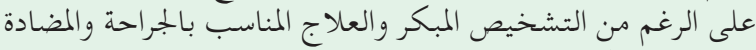

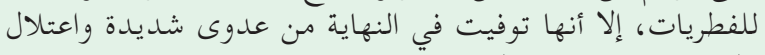

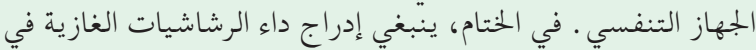

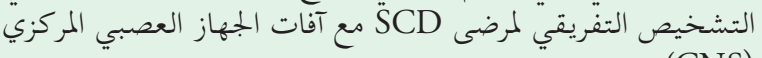

(CNS)

To describe a fatal case of invasive Aspergillus flavus sinusitis in a 43-year old female with sickle cell disease (SCD) complicated by intracerebral aspergilloma and invasive Salmonella infection. Cerebral aspergilloma carries a very high mortality rate. The patient developed post-craniotomy intracerebral hemorrhage at the site of biopsy, Salmonella species sepsis and ventriculitis. She presented with a 2-month history of headache, dizziness, personality and behavioral changes, and vomiting. Initial clinical evaluation raised the suspicion of brain tumor. Brain magnetic resonance imaging revealed a left frontal, thick-walled ring-enhancing lesion with extensive surrounding edema suggestive of a neoplastic lesion, or a contiguous inflammatory or infectious process from the skull base. Despite early diagnosis and appropriate antifungal and surgical management, she eventually died from severe infection and respiratory arrest. In conclusion, invasive aspergillosis should be included in the differential diagnosis of SCD patients with central nervous system (CNS) lesions.
Saudi Med J 2018; Vol. 39 (9): 935-939

doi: 10.15537/smj.2018.9.22821

From the Department of Pathology and Laboratory Medicine, College of Medicine, King Saud University and King Saud University Medical City, Riyadh, Kingdom of Saudi Arabia.

Received 6th May 2018. Accepted 25th July 2018.

Address correspondence and reprint request to: Dr. Fawzia E. Alotaibi, Department of Pathology and Laboratory Medicine, College of Medicine, King Saud University and King Saud University Medical City, Riyadh, Kingdom of Saudi Arabia. E-mail: ofawzia@ksu.edu.sa ORCID ID: orcid.org/0000-0002-7173-5237

O erebral aspergillosis, including infection of the sinuses is a serious infection and difficult to diagnose because it is usually misdiagnosed as tumor and is associated with high mortality. ${ }^{1,2}$ Surgical exploration and intra-operative diagnosis is required for accurate diagnosis and is made by histopathological examination. ${ }^{2}$ Early surgical intervention and aggressive antifungal treatment are considered as cornerstone management strategies. ${ }^{2}$ Aspergillosis of the sinuses is a spectrum of diseases that range from local infection involving the sinuses to invasive aspergillosis with extension to the brain and orbit. ${ }^{3,4}$ Invasive aspergillosis affects primarily immunocompromised hosts and rarely immunocompetent individuals. ${ }^{1-7}$ Causes of Immunosuppression such as hematological malignancies, prolonged neutropenia and solid organ transplant are among the recognized risk factors for invasive aspergillosis. ${ }^{1-6}$ Hematogenous dissemination of the infection to the brain or directly via the paranasal sinuses is associated with poor prognosis. ${ }^{3-7}$ Cerebral abscess and ventriculitis caused by Salmonella species as a postoperative complication of craniotomy associated with fungal infection are extremely rare. This report presents the challenge of postoperative infectious complications in patients presenting with cerebral aspergillosis. It describes an unusual case of invasive 
aspergillosis of the paranasal sinuses involving the brain in a sickle cell disease (SCD) patient who eventually died because of post-craniotomy Salmonella ventriculitis, abscess collections and severe brain edema. The rapid clinical progression and complications of invasive sinusitis presented in this case highlight the importance of early diagnosis and initiation of antifungal treatment in such cases. This is a case report of invasive aspergillosis in a SCD patient from the Middle East region.

Case Report. Patient information. A 43-year-old female, a known case of SCD, presented to the Emergency room with a 2-month history of headache, dizziness, personality and behavioral changes, and recurrent vomiting.

Clinical findings. Physical examination revealed an axillary temperature of $37.4^{\circ} \mathrm{C}$; heart rate $156 \mathrm{bpm}$; respiratory rate $22 \mathrm{cpm}$; blood pressure 112/84 $\mathrm{mmHg}$; and $\mathrm{SpO}_{2} 99 \%$. She was examined by the ear, nose, and throat (ENT) specialist, and endoscopic evaluation of the sinuses suggested that the sinuses was the source of infection.

Diagnostic assessment. Functional endoscopic sinus surgery was performed and endoscopic examination of the left nostril showed slough and dead tissue; pus was seen in the frontal sinus and the mucosa was unhealthy. During examination, she underwent debridement of the slough and dead tissue of the sphenoidal sinus, periorbita and septum mucosa. Local intranasal ceftriaxone and caspofungin were used during debridement of the sinuses. A brain computed tomography (CT) scan revealed a left frontal intra-axial thick-walled ring-enhancing lesion with extensive surrounding edema, possibly a high-grade neoplastic lesion (glioma) involving the corpus callosum, or a contiguous inflammatory or infectious process originating from the skull base. There were also bony and dural changes along the anterior skull base with erosion of the sella turcica and lateral sphenoid bone toward the cavernous sinus (Figure 1). Initial clinical and radiological evaluation raised the suspicion of a brain tumor. Based on clinical examination, the decision was to perform a craniotomy and excisional biopsy of the frontal lobe lesion for diagnostic and therapeutic

Disclosure. Authors have no conflict of interests, and the work was not supported or funded by any drug company.

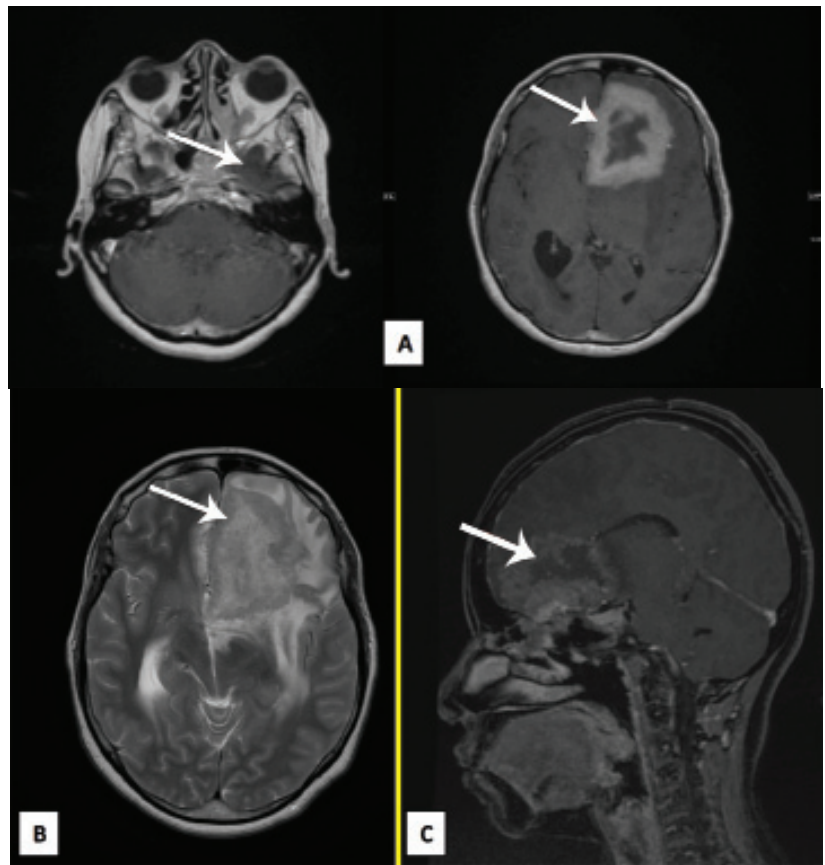

Figure 1 - Post contrast administration MRI-Brain; A) Axial T1WI, A large mass lesion is noted in left frontal lobe, measuring about $6 \times 5 \mathrm{~cm}$. B) Axial T2WI, There is dural thickening and enhancement along the left cribriform plate, tuberculum sella and floor of sella. Mucosal thickening and abnormal density is noted in the sphenoid sinus and the left sphenoid sinus with well demarcated osseous defect on left side. C) Sagittal T1WI, bony and dural changes along the anterior skull base and left frontal intra-axial mass thick-walled ring enhancing lesion with extensive surrounding edema possibly aggressive neoplastic lesion, or less likely contiguous inflammatory or infectious process from skull base.

purposes. The risks associated with the surgery included infection, bleeding, recollection of abscesses, and recurrence. During surgery, a neuronavigation-guided frozen section of the brain lesion was performed which was sent to the histopathology laboratory. The intraoperative diagnosis was left granulomatous invasive fungal sinusitis with erosion of the sella turcica and lateral sphenoid bone toward the cavernous sinus. A granuloma was observed histologically and a few days later, cultures from the brain lesion and nasal tissue yielded many septate branching fungal hyphae identified as Aspergillus flavus (Figure 2). The fungus was resistant to amphotericin B (minimum inhibitory concentration $(\mathrm{MIC}=2 \mu \mathrm{g} / \mathrm{mL})$, and susceptible to voriconazole $(\mathrm{MIC}=0.12 \mu \mathrm{g} / \mathrm{mL})$, itraconazole $\quad(\mathrm{MIC}=0.12 \mu \mathrm{g} / \mathrm{mL})$ and posaconazole $(\mathrm{MIC}=0.06 \mu \mathrm{g} / \mathrm{mL})$. Aspergillus antigen test (galactomannan and $\mathrm{IgG}$ ) yielded negative results. The final diagnoses, based on culture findings were invasive sinus aspergillosis and intracerebral aspergilloma. 


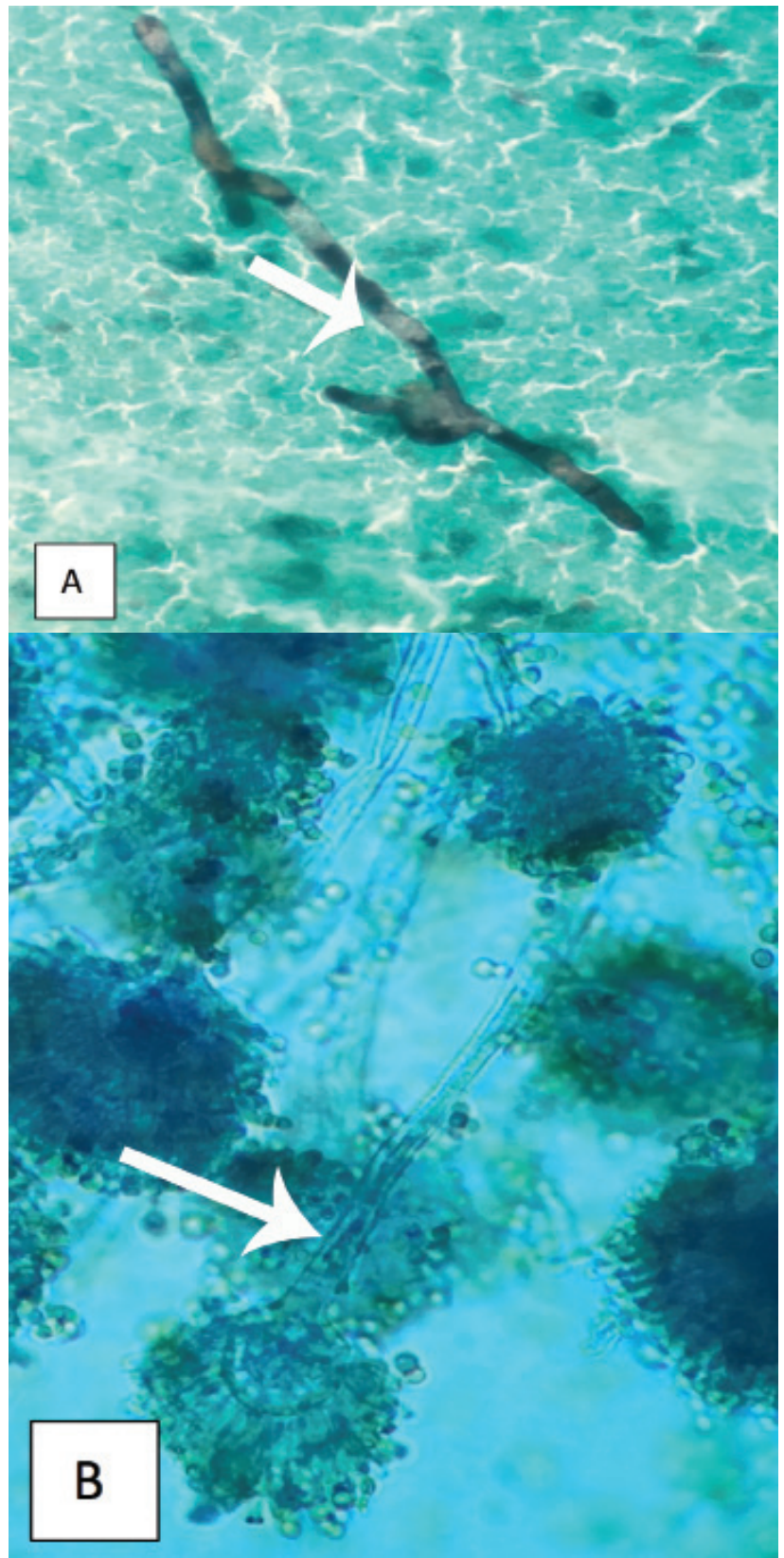

Figure 2 - Photomicrograph of the brain lesion showing A) branched and septate fungal hyphae typical of aspergillosis in Grocott's methenamine silver stain. B) aspergillus flavus conidiophore bearing vesicle (phialides arise circumferentially from the globose vesicle) in Lactophenol cotton blue (LPCB).

Therapeutic intervention. Unfortunately, diagnostic endonasal sinus debridement was incomplete due to extensive infection that might spread to involve the cavernous sinus on aggressive management. Therefore, she underwent surgery (craniotomy) and repeated debridements were also carried out. Post-operatively, she tolerated the operation well, she was intubated and transferred to the surgical intensive care unit for observation and started on antifungal medication voriconazole $(600 \mathrm{mg} /$ day $)$ and caspofungin $(70 \mathrm{mg} /$ day IV) and $(50 \mathrm{mg} /$ day IV) thereafter.

Follow up and outcomes. She was afebrile, she had no basal discharge, she could move all limbs and was taking orally. Her Glasgow coma scale (GCS) score was $15 / 15$ with no focal neurological deficit. The wound was clean and dry. She received cefazolin, dexamethasone, haloperidol (2.5 mg, IM, q6hr), metoclopramide (10 $\mathrm{mg}, \mathrm{q} 8 \mathrm{hr}$ ), and phenytoin (100 $\mathrm{mg}, \mathrm{IV}, \mathrm{q} 8 \mathrm{hr}$ ). In the context of her clinical condition, vasculitis screening for antineutrophil cytoplasmic antibodies, antinuclear antibody, HIV test and CD4 count was requested. The results revealed reduced levels of IgG and IgM. Consultation with an immunologist suggested that the low immunoglobulin level could explain her underlying fungal infection. Seven days after surgery she showed decreased level of consciousness due to intracerebral hemorrhage at the biopsy site and sepsis caused by Gram-negative bacilli. She became febrile, tachycardic, and had leukocytosis (white blood cell [WBC] count, $12.34 \times 10^{9} / \mathrm{L}$ ). She was evaluated by the infectious diseases and ENT specialists. Her renal function tests showed high creatinine (150 $\mu \mathrm{mol} / \mathrm{L})$ and blood urea nitrogen levels. Because of her new symptoms, she underwent a second craniotomy which revealed subgaleal, left epidural and subdural and intraventricular abscesses that were evacuated and irrigated thoroughly. Pure pus drained after insertion of an external ventricular drain in the right frontal abscess. Specimens were collected during surgery and pus from abscesses and tissue samples were sent for culture and histopathology. Cerebrospinal fluid (CSF) analysis showed a red blood cell count of $50 / \mathrm{mm} 3$ and WBC $700 \times 10^{6} / \mathrm{L}$ (90\% polymorphs and $10 \%$ mononuclear cells). All cultures of specimens including blood, stool, CSF, brain abscess, and scalp wound yielded ampicillin and ciprofloxacin-resistant (MIC $=0.094 \mu \mathrm{g} /$ $\mathrm{mL}$, Nalidixic Acid=R) group B Salmonella species. Intravenous (IV) ceftriaxone (2 g) 12-hourly was started. A brain CT scan showed purulent fluid, edema with subsequent mass effect on the frontal horn of the lateral ventricles and a small suspicious communication with the left frontal horn and abscess collection in the left lateral ventricle with mild enhancement of the ventricular outlines suggestive of ventriculitis (Figure 3). The patient developed seizures triggered by sepsis and neuroleptics. Her clinical condition deteriorated over time due to Salmonella sepsis and ventriculitis, renal 
impairment, malnutrition, pancytopenia and high risk of aspiration pneumonia. She was intubated, drowsy (GCS: 11/15), moved all 4 limbs, grasped both hands on command, and had symmetric and reactive pupils. She exhibited convulsive movements of the left eyelids and right distal foot. Despite aggressive management, the patient died due to severe infection and respiratory arrest. A timeline table showing the progress of the patient since admission and throughout the hospitalization course is shown in (Table 1).

Discussion. Invasive aspergillosis is a fatal infection that commonly affects immunocompromised hosts. Individuals at the highest risk of acquiring invasive aspergillosis include patients with leukemia during induction therapy; solid organ transplant, prolonged neutropenia, immunodeficiency, and corticosteroid use. ${ }^{1-3}$ Invasive aspergillosis is rare in immunocompetent individuals. $^{5-7}$

Although no clear association exists in the literature between SCD and invasive aspergillosis, SCD is suggested to have contributed to the pathogenesis of invasive aspergillosis in the present case. In addition, her underlying hematological disease combined with the incomplete sinus debridement, Intensive care
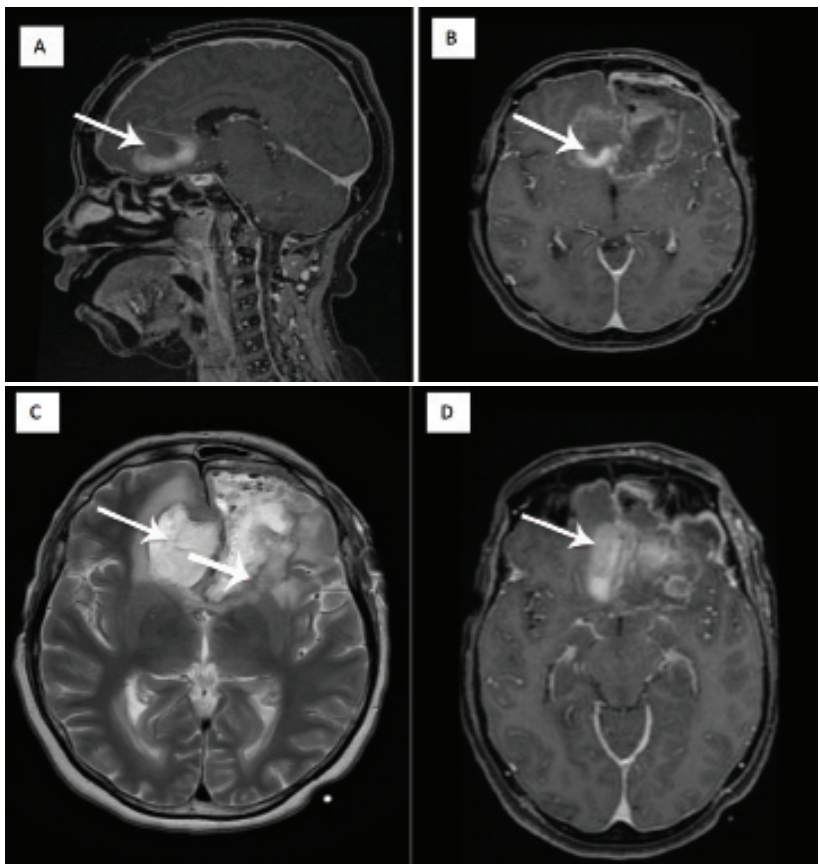

D

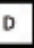

Figure 3 - Postoperative MRI-Brain. Complex signal abnormality noted at the surgical bed at bifrontal (A) and (B), region most likely representing subacute blood, some purulent fluid, pneumocephalus and edema with possible communication with the left lateral ventricle (C) and (D). No brain infarction or venous sinus thrombosis.

Table 1 - A timeline table showing the progress of the patient since admission and throughout the hospitalization course.

\begin{tabular}{|c|c|c|c|c|}
\hline Relevant past & Dates & Initial and follow-up visits & Diagnostic testing (including dates) & Interventions \\
\hline \multirow{5}{*}{$\begin{array}{l}\text { A 43-years old } \\
\text { female, know } \\
\text { case of Sickle cell } \\
\text { disease (SCD). }\end{array}$} & $19 / 5 / 2015$ & $\begin{array}{l}\text { Presented to the emergency room } \\
\text { complaining of } \\
\text { Headache. } \\
\text { Dizziness, personality and } \\
\text { behavioral changes, vomiting } \\
\text { on and off for two months. }\end{array}$ & $\begin{array}{l}\text { Functional endoscopic sinus surgery } \\
\text { (FESS) } \\
19 / 5 / 2015\end{array}$ & $\begin{array}{l}\text { Debridement of the slough and } \\
\text { dead tissue of the sphenoidal sinus, } \\
\text { periorbita and septum mucosa. } \\
\text { Local ceftriaxone and caspofungin. }\end{array}$ \\
\hline & $21 / 5 / 2015$ & $\begin{array}{l}\text { Initial clinical and radiological } \\
\text { evaluation raised the suspicion of } \\
\text { brain tumor. }\end{array}$ & $\begin{array}{l}\text { - } \quad \text { CT-scan brain } \\
\text { MRI brain Axial T1WI } \\
\text { post contrast administration } \\
21 / 5 / 2015\end{array}$ & $\begin{array}{l}\text { - Craniotomy and excisional biopsy of } \\
\text { the frontal lobe lesion for diagnostic } \\
\text { and therapeutic purposes. } \\
\text { Intubated and transferred to the } \\
\text { Surgical Intensive care unit. }\end{array}$ \\
\hline & $22 / 5 / 2015$ & $\begin{array}{l}\text { Granuloma was seen by histology } \\
\text { and cultures from the brain lesion } \\
\text { and nasal tissue grew Aspergillus } \\
\text { flavus. }\end{array}$ & $\begin{array}{l}\text { - Cultures from the brain lesion } \\
\text { and nasal tissue. } \\
\text { - Histology, 22/5/2015 }\end{array}$ & $\begin{array}{l}\text { - } \quad \text { Voriconazole ( } 600 \mathrm{mg} / \text { day }) \text {. } \\
\text { caspofungin ((70 mg day } 1 \mathrm{IV} \text { and } \\
50 \mathrm{mg} / \text { day IV thereafter })\end{array}$ \\
\hline & $26 / 5 / 2015$ & $\begin{array}{l}\text { Decreased level of consciousness } \\
\text { due to intracerebral hemorrhage at } \\
\text { the biopsy site and sepsis caused by } \\
\text { gram-negative bacilli. }\end{array}$ & $\begin{array}{l}\text { Second craniotomy revealed } \\
\text { intraventricular abscesses. } \\
\text { 26/5/2015 } \\
\text { Abscesses and tissue samples } \\
\text { sent for culture and histology. } \\
\text { 26/5/2015 }\end{array}$ & $\begin{array}{l}\text { Intraventricular abscesses evacuated } \\
\text { and irrigated thoroughly. } \\
\text { Intravenous (IV) ceftriaxone } 2 \mathrm{~g} \\
\text { 12-hourly. }\end{array}$ \\
\hline & $27 / 5 / 2015$ & $\begin{array}{l}\text { The patient developed seizures } \\
\text { triggered by sepsis and neuroleptics. } \\
\text { She deteriorated over time due to } \\
\text { Salmonella sepsis and ventriculitis. }\end{array}$ & $\begin{array}{l}\text { Brain CT-scan } \\
27 / 5 / 2015\end{array}$ & $\begin{array}{l}\text { The patient died because of severe } \\
\text { infection and respiratory arrest. }\end{array}$ \\
\hline
\end{tabular}


unit admission, and surgical interventions triggered a complicated clinical course including intracerebral aspergilloma and Gram-negative Salmonella bacteremia. Additionally, multiple catheterization, abnormal renal function and mechanical ventilation might have adversely affected the immune function and led to the poor outcome.

The most frequent symptoms in patients with Central Nervous System (CNS) aspergillosis are headache, vomiting, convulsions, fever, and cranial nerve paralysis. Our patient presented mainly with prolonged headache and dizziness. This suggests that in SCD patients, such history should raise the clinical suspicion of possible fungal infection caused by Aspergillus species. In addition, environmental factors including airborne mold concentrations, geographic location, and constructional work may influence IA development. ${ }^{8}$

An interesting magnetic resonance imaging finding in this case is the observation of irregularity and mild narrowing of the arteries of the circle of Willis, including the terminal internal carotid, proximal middle cerebral, anterior cerebral and posterior cerebral arteries due to the patient's SCD. We proposed that might be the reason for the rapid progression and invasiveness of the fungal infection in this case.

Voriconazole, isavuconazole and amphotericin B are the antifungal agents used for the first-line treatment of IA. ${ }^{9,10}$ Caspofungin have been shown to exert in vitro and in vivo activity against Aspergillus spp and is approved for the treatment of IA in patients who are intolerant to first-line therapy. ${ }^{9}$ Our patient was treated with voriconazole and caspofungin. Combination therapy with voriconazole and caspofungin in treatment of CNS aspergillosis is promosing. ${ }^{10}$ However, we believe that, the severity of infection, coinfection with Salmonella ventriculitis and sepsis contribute to the poor outcome in this patient.

In conclusion, invasive aspergillosis should be included in the differential diagnosis of SCD patients with CNS lesions, particularly if presented with chronic symptoms suggestive of CNS involvement. Rapid diagnosis and aggressive medical and surgical management are of the utmost importance.
Acknowledgment. We would like to thank Editage (http:// www.editage.com/) for English language editing.

\section{References}

1. Taccone FS, Van den Abeele AM, Bulpa P, Misset B, Meersseman W, Cardoso T, et al. Epidemiology of invasive aspergillosis in critically ill patients: clinical presentation, underlying conditions, and outcomes. Crit Care 2015; 19: 7.

2. Alsalman J, Zaid T, Makhlooq M, Madan M, Mohamed Z, Alarayedh A. A retrospective study of the epidemiology and clinical manifestation of invasive aspergillosis in a major tertiary care hospital in Bahrain. J Infect Public Health 2017; 10: 49-58.

3. Baeesa SS, Bokhari RF, Alghamdi KB, Alem HB, Al-Maghrabi JA, Madani TA. Invasive aspergillus sinusitis with orbitocranial extension. Asian J Neurosurg 2017; 12: 172-179.

4. Jariwal R, Heidari A, Sandhu A, Patel J, Shoaepour K, Natarajan $\mathrm{P}$, et al. Granulomatous Invasive Aspergillus flavus Infection Involving the Nasal Sinuses and Brain. J Investig Med High Impact Case Rep 2018; 6: 2324709618770473.

5. Ahmadzai H, Raley DA, Masters L, Davies M. An unusual case of a pituitary fossa aspergilloma in an immunocompetent patient mimicking infiltrative tumour. J Surg Case Rep 2013; 2013: rjt018.

6. Ouyang T, Zhang N, Wang L, Jiao J, Zhao Y, Li Z, et al. Primary Aspergillus sellar abscess simulating pituitary tumor in immunocompetent patient. J Craniofac Surg 2015; 26: e86-e88.

7. Bangash M. Aspergillus flavus Brain Abscess in Immunocompetent Teenagers: A Case Series with Review of Literature. Journal of Case Reports 2017; 7: 8-12.

8. Garcia-Vidal C, Peghin M, Cervera C, Gudiol C, Ruiz-Camps I, Moreno A, et al. Causes of death in a contemporary cohort of patients with invasive aspergillosis. PLoS One 2015; 10: e0120370.

9. Patterson TF, Thompson GR 3rd, Denning DW, Fishman JA, Hadley S, Herbrecht R, et al. Practice Guidelines for the Diagnosis and Management of Aspergillosis: 2016 Update by the Infectious Diseases Society of America. Clin Infect Dis 2016; 63: e1-e60.

10. Bassetti M, Peghin M, Vena A. Challenges and Solution of Invasive Aspergillosis in Non-neutropenic Patients: A Review. Infect Dis Ther 2018; 7: 17-27. 